\title{
US Government Textbook Review
}

\author{
Katherine Knutson, Gustavus Adolphus College
}

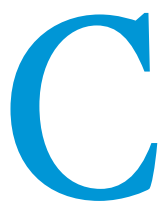

hoosing an American government textbook is a daunting task. A quick search of leading textbook publishers reveals over 40 different texts, each with multiple versions (brief, essential, loose leaf, ebook, and more.) and online "learning experiences." Texts vary widely in approach, tone, supplemental resources, and price. To date, there is no comprehensive review of American government texts, though many scholars have examined coverage of various topics including gender (Olivo 2012; Cassese, Bos, and Schneider 2014; Eksterwicz and Watson 2000), religion (Fairbanks 1986; Eisenstein and Clark 2013), race (Monforti and McGlynn 2010; Wallace and Allen 2008; Allen and Wallace 2010), sexual orientation (Novkov and Gossett 2007), bureaucracy (Lorenzo 1999; Goldstein 1985), the presidency (Evans and Lindrum 2013), economics (Madsen 2011), and the founding (Eksterowicz and Cline 1991; Franke and Bagby 2005).

Instructors of introductory American government courses approach the subject from different perspectives; our subfields and methodological approaches vary and the things we value in a text differ widely. This review does not satisfy the need for a comprehensive comparison of all the texts on the market, but examines five leading texts (see table 1), comparing their guiding perspectives, structure, in-text and electronic features for students and faculty, and notable strengths and weaknesses with the goal of identifying appealing texts for instructors who value different approaches.

\section{We The People, 1oth Edition. By Benjamin Ginsberg, Theodore J. Lowi, Margaret Weir, and Caroline J. Tolbert. New York: W.W. Norton \& Company. 761 p. \$147 cloth.}

We the People asks why should students be engaged in the political process. The authors argue students have personal interests at stake in politics and the text explores ways for students to engage in the political process in pursuit of those interests. The emphasis on civic engagement and participation shapes the overall structure of the book, with sections related to political behavior preceding the institution chapters. Each chapter opens with a brief overview of the ways government is involved in the particular area and the impacts of that involvement. Overviews provide specific examples from contemporary politics to give readers a sense of how the topic impacts contemporary debates without going into great detail on a single issue.

The text contains four main sections. The first section includes separate chapters on American political culture, the Constitution, federalism, civil liberties, and civil rights. These chapters set the tone for the book, emphasizing politics as conflict over ideas and values and affirming the importance of citizen engagement. The second section contains chapters on public opinion, media, participation and voting, parties and elections, and groups and interests. The structure of chapters within this section reflects the overall perspective of the book. As the authors state in the preface, they try to "make politics interesting by demonstrating that students' interests are at stake and that they therefore need to take a personal, even selfish, interest in the outcomes of government" (xix, italics added). The politics section reflects this approach by giving primacy to individual political engagement in chapters on public opinion, media consumption, and voting before exploring ways in which individuals organize collectively through political parties and organized groups. The third section includes chapters focused on Congress, the presidency, the bureaucracy, and courts. The final section, focused on public policy, includes separate chapters focused on economic, social, and foreign policy. ${ }^{1}$ These chapters provide a brief overview of most major policy areas including taxes, the environment, health care, education, welfare, housing, humanitarian aid, and national security.

The text contains several unique features included in each chapter designed to help students think critically about information. These sections also provide instructors with the opportunity to teach basic quantitative literacy skills. Each chapter includes a comparative perspective in a sidebar. "Who Are Americans?" examines a topic raised in the chapter using vibrant graphics to answer a demographic question. Each chapter ends with an invitation to "plug in" through suggested ways to "inform," "express," "connect," and "act." These give students tangible, but not difficult or time consuming, ways to get involved in the political process. As the title of the section suggests, the calls to action are largely centered on electronic forms of participation. This section follows the general theme of the book in emphasizing individual belief and action over group action and centering most calls to action on things you can do from the couch with a laptop. Even the "connect" suggestions are largely informational in nature, directing students to discover what other people think about an idea but, for the most part, not asking them to engage directly with other people.

The book itself is a wealth of reference information. The front pages include full color maps of the party breakdown in the 114th Congress for both the House and Senate and the back pages list voter registration information for all 50 states and the District of Columbia. The appendix includes the Declaration of Independence, Articles of Confederation, Constitution, Federalist Papers (10 and 51), Anti-Federalist Papers, a list of presidents and vice presidents, and a comprehensive glossary.

Learning resources for students are strong. Key terms are highlighted in bold, with definitions provided in the margins. 
Each chapter includes a study guide complete with a summary of each section of the chapter, a list of key terms with corresponding page numbers, and practice multiple choice questions. The study guide includes selections for further references to scholars or studies. For instructors looking for a text focused on political behavior and participation (particularly in the internet age), We the People offers a comprehensive and highly readable option, though one that will

\section{Each chapter ends with an invitation to "plug in" through suggested ways to "inform," "express," "connect," and "act." These give students tangible, but not difficult or time consuming, ways to get involved in the political process.}

reading-both classics and more recent publications-and recommended websites. Online, students have access to InQuizitive, a virtual study space that feels more like a computer game than a study session, with target scores, confidence wagers, and multiple levels. Unlike some other online resources, InQuizitive is not designed to factor into a students' grade, though instructors might consider making completion of activities a small part of a course participation grade.

Instructors have access to the standard array of online support materials including an instructor's manual, test bank, and PowerPoint slides. Coursepack materials are available for Blackboard, Angel, D2L, Moodle, and Canvas and these resources include exercises, simulations, and graphics. In addition to the full edition reviewed here, We the People comes in Core and Essentials versions and in bound, loose leaf, or ebook formats. The alternative versions are appealing because they offer a significantly lower price point for faculty who are concerned about cost. The Core version contains the first three sections of the full version but omits the policy chapters. The Essentials version is a condensed version of the original with several merged chapters (a single chapter for civil liberties and civil rights and for parties, participation, and elections) and two policy chapters (domestic and foreign policy).

This text is grounded in research but, for the most part, students will have to dig through endnotes to find specific

Table 1

\section{Books Reviewed in this Article}

We The People, 10th Edition. By Benjamin Ginsberg, Theodore J. Lowi, Margaret Weir, and Caroline J. Tolbert. New York: W.W. Norton \& Company. 761 p. \$147 cloth.

The Logic of American Politics, 7th Edition. By Samuel Kernell, Gary C. Jacobson, Thad Kousser, and Lynn Vavreck. Los Angeles: Sage/CQ Press, 2016. 722p. \$106 paper.

The Struggle for Democracy, 2014 Elections and Updates Edition. By Edward S. Greenberg and Benjamin I. Page. Boston: Pearson. 694 p. \$185 paper.

American Government: Roots and Reform, 2014 Elections and Updates Edition. By Karen O'Connor, Larry J. Sabato, and Alixandra B. Yanus. Boston: Pearson. 647 p. \$179 paper.

American Government: Institutions and Policies, 15th Edition By James Q. Wilson, John J. Dilulio, Jr., Meena Bose, and Matthew Levendusky. Boston: Cengage. 524 p. \$266 paper. emphasize individual and electronic participation over group and in-person participation.

\section{The Logic of American Politics, 7 th Edition. By Samuel Kernell, Gary C. Jacobson, Thad Kousser, and Lynn Vavreck. Los Angeles: Sage/CQ Press, 2016. 722p. \$106 paper.}

The Logic of American Politics takes a rational choice approach to American government, illuminating the constraints shaping the political process. This central theme is detailed in the opening chapter of the text, which provides an overview of rational choice theory and defines key concepts, including collective action, free rider problem, and transaction costs, used throughout the book. Emphasizing the complexities of politics and the constraints facing anyone attempting to make policy change, the text is somewhat pessimistic in its final outlook. However, the authors argue that understanding the logic driving American politics is critical in the process of initiating policy change.

Following the opening chapter, the text is divided into three sections. The order of these sections reflects the text's focus on institutions as a primary factor shaping the decision making context. The first section of the text includes chapters on the Constitution, federalism, civil rights, and civil liberties. Section two focuses on political institutions, with separate chapters on Congress, the presidency, the bureaucracy, and the federal judiciary. Section three includes chapters on public opinion; voting, campaigns, and elections; political parties; interest groups; and the media. The concluding chapter doubles as a policy chapter, reemphasizing the collective action framework through an analysis of several major policy areas including health care, climate change, the Fiscal Cliff, entitlement reform, and tax policy. The appendix includes the Articles of Confederation, Declaration of Independence, Constitution, Federalist 10, and Federalist 51.

Each chapter begins with a set of framing questions addressed in the chapter. These questions are a helpful way to get students to think critically about the upcoming chapter and, because they are essentially research questions, they help model the process of scientific inquiry that begins with asking good questions. The text could build more on the research process it introduces through these opening questions by identifying more specific research findings and authors in the text, though this information is available to students in the endnotes. Opening vignettes range from contemporary issues to historical debates. Students are clued in to the application of the collective action framework throughout the book 
through the use of blue text in areas where the framework is clearly applied. Sidebars within each section also provide a collective action analysis to both historical and contemporary questions. The "Politics to Policy" sections included in many chapters analyze how political decisions are shaped by the constraints of political institutions. "Logic of Politics" uses rational choice theory to explain the logic of political outcomes such as bureaucratic scandals, senate confirmation battles, or the absence of strong third-parties. "Strategy and Choice" focuses on how politicians and other political actors respond to the incentives created by institutional constraints. might also appeal to those who want to attune students to the important role of political institutions or who want ample historical coverage, as this text excels in both.

\section{The Struggle for Democracy, 2014 Elections and Updates Edition. By Edward S. Greenberg and Benjamin I. Page. Boston: Pearson. 694 p. $\$ 185$ paper.}

Framed through the lens of democratic theory, The Struggle for Democracy asks, "how democratic are we?" and "can government do anything well?" Despite the ostensibly pessimistic opening question, the text presents a relatively positive view

\section{Students are clued in to the application of the collective action framework throughout the book through the use of blue text in areas where the framework is clearly applied. Sidebars within each section also provide a collective action analysis to both historical and contemporary questions.}

Students are alerted to important terms and concepts bolded in the text and listed at the end of each chapter, with a full glossary at the end of the book. The text does not include chapter summaries or practice quizzes, but students are directed to online resources through SAGE Edge. ${ }^{2}$ Here students can access chapter summaries, electronic flashcards, and practice quizzes for each chapter. SAGE Edge includes several short video clips for each chapter that connect directly to concepts discussed in the text. Students also have access to selected SAGE journal articles for each chapter. Both the video clips and journal articles include a set of reflection and discussion questions to help students connect the supplemental material to the questions and concepts discussed in the text. Any of these would be appropriate for homework assignments or in class activities. Each chapter does include a list of suggested readings, but the items listed in most chapters are dated and students may find the corresponding SAGE articles more timely.

Online resources for faculty include sample syllabi, editable PowerPoint slides (instructors must add all photos), access to all tables and figures from the text, data literacy exercises, skill building exercises, class exercises and writing assignments, an instructors manual and a test bank (available in Microsoft Word, Respondus, and Diploma). Course cartridges are also available, which allow instructors to upload all of the instructor resources to one of five main learning management systems (including Blackboard, Moodle, and D2L). Like students, instructors also have access to full-text SAGE journal articles.

Unlike most of the other texts reviewed here, The Logic of American Politics does not come in alternate formats, but it is also one of the lower priced full-text options coming in at just over $\$ 100$ for a new paperback. Because of the emphasis on theory and analysis, the reading level of the text is challenging, though not inappropriate for an introductory level college course. Instructors interested in a more sophisticated and theory-driven analysis of traditional American government fare may be particularly interested in this text. The text of government while emphasizing the structural constraints facing those who wish to make change. The goal of the text is for students to recognize public policy, in its various forms, as an outcome of the interplay of structural factors and democratic participation. Through it all, students are asked to critically consider the processes by which decisions are made in a democratic society and the extent to which these outcomes are more or less democratic.

The text is divided into four substantive sections with a separate introductory chapter. The introduction presents the concept of democracy and outlines an analytical framework for understanding American politics. This framework appears throughout the text and explains government action as the result of the compounding forces of the structural environment, political linkages between people and government, and government institutions. The substantive sections, themselves, are organized according to the framework presented in the introduction, giving coherence to the entire text, but also making it difficult to rearrange the order of topics. If you prefer to cover institutions before political behavior, this is not the book for you.

The first of four substantive sections includes chapters on the Constitution, federalism, and a chapter exploring demographics and political culture. Absent are the usual chapters on civil rights and civil liberties; these are treated as policy outputs and included in the final section of the text. The second section includes chapters on public opinion; media; interest groups and business; social movements; political parties; and voting, campaigns, and elections. The media chapter is noteworthy because it focuses on new media, bypassing much of the historical focus or questions about government regulation of media that are common in most American government texts. The inclusion of a stand-alone chapter on social movements in this section, which addresses both historical and contemporary movements, is also a distinguishing feature of the text. The third section includes chapters on Congress, the president, the executive, and the courts. The final section explores government action with chapters on civil liberties, civil rights, 
domestic policy, and foreign policy. The appendix includes the Declaration of Independence, Constitution, Federalist Papers 10, 51, and 78, and a list of presidents and party control of Congress.

Each chapter contains several features designed to develop critical thinking and analysis skills. The "Framework" section, included in each chapter, builds on the overall structure of the text by analyzing a policy decision (or indecision) using the four categories: structure, political linkage, government, and government action. Other sections within the chapters seek to develop critical thinking and quantitative literacy skills. "Mapping American Politics" uses cartograms to explore various topics. "By the Numbers" presents social science data used to explain questions such as how attendance at protests or poverty are measured. Many chapters include a timeline exploring a particular aspect of the topic raised in the text. packaged together and, as a result, is easier to maneuver. Students read through the ebook (or have it read to them), taking quizzes along the way to assess their understanding of the material. Graphics are interactive and students can respond directly to questions posed by the text.

Faculty have access to a variety of online resources including a downloadable instructor's manual, test bank (with modules for Blackboard and WebCT only, though PDF and Word versions are also available), PowerPoint slides, and sample syllabus. Faculty can customize certain aspects of both MyPoliSciLab and REVEL, selecting assignments, setting deadlines, and monitoring class performance. As with the student interface, the faculty interface for REVEL is easier than MyPoliSciLab to navigate. Instructors can rearrange the order of the chapters, set due dates for reading and assignments, require students to complete assignments, and track student

\section{The "Framework" section, included in each chapter, builds on the overall structure of the text by analyzing a policy decision (or indecision) using the four categories: structure, political linkage, government, and government action.}

The two overarching questions raised by the text are addressed in each chapter. "Can Government Do Anything Well?" explores topics ranging from environmental protection to health care for veterans. After a brief overview of the topic, the text provides side-by-side lists of arguments supporting competing answers to the question. Each chapter ends with "Using the Democracy Standard," featuring a question that ties the theme of democratic theory to the chapter topic. The authors do not directly answer these questions, but rather students are presented with various forms of evidence and asked to draw their own conclusions. Some chapters build on this approach of providing students with multiple perspectives by summarizing key debates within the academic literature. For example, the chapter on voting presents several competing models explaining voting decisions. Other chapters would benefit from explicit acknowledgement of areas of disagreement among scholars.

Students are aided in the learning process through bolded terms and definitions in the margins. A quiz at the end of each chapter allows students to assess their retention of the material. The resources section includes an annotated list of internet sources and other readings. The Struggle for Democracy comes only in the full edition and it can be packaged with one of two online learning experiences supported by Pearson: MyPoliSciLab or REVEL. Both systems are compatible with most online learning management systems. The primary difference between the two is that REVEL combines the student resources with an interactive ebook whereas the two resources are separated in MyPoliSciLab. MyPoliSciLab has been around for many years and contains a number of useful features including quizzes, simulations, supplementary videos, and exams. However, the interface is not user friendly and students must jump between windows to access various information. In contrast, REVEL has all the information progress. For instructors concerned about cost, electronic or loose leave versions of the text offer considerable savings over the standard text.

The Struggle for Democracy offers an engaging and accessible option for instructors who prefer a focus on political institutions, democratic theory, and political engagement. The framework theme, emphasizing structure, political linkage, government, and government action, provides a coherent and integrated structure for the text. Sections within each chapter reinforce this analytic approach and give students opportunities to practice this type of analysis. While the text includes some historical context, the emphasis is focused on contemporary trends. The text pushes students to consider important questions and refrains from driving them to a particular conclusion. The separate chapters on interest groups and social movements reinforce the emphasis on the importance of group engagement in the political process and are appealing to those who wish to spend more time exploring collective action from something other than a rational choice perspective.

\section{American Government: Roots and Reform, 2014 Elections and Updates Edition. By Karen O'Connor, Larry J. Sabato, and Alixandra B. Yanus. Boston: Pearson. 647 p. \$179 paper.}

American Government: Roots and Reform frames current political events and government structure through a historical lens, emphasizing the historical context of the material discussed within each chapter. Chapters begin with the historical roots of the topic and end with the question of what reform might look like moving into the future. The emphasis on context is reiterated with the opening photos in each chapter which juxtapose scenes from history with a contemporary version of the event.

The text is divided into four sections. The first section includes an introductory chapter focused on political culture 
and separate chapters examining the Constitution, federalism, civil liberties, and civil rights. A notable strength of this text is its exceptional coverage of local government in the chapter on federalism. Most American government texts gloss over the topic even though local government is the part of government that students will likely have the most contact with over the course of their life. The institutions section includes standard chapters on Congress, the presidency, the bureaucracy, and the judiciary. The third section features chapters on public opinion and socialization, political parties, elections and voting, campaigns, media, and interest groups. Whereas many texts lump information about campaigns, elections, and voting together, this text separates these topics into two separate chapters, allowing for a more robust analysis of each topic. The final section, focused on policy, includes separate chapters addressing domestic policy, economic policy, and foreign policy. The domestic policy chapter introduces the policy cycle, providing a theoretical framework for discussion of health policy, education policy, and energy/environment policy in the chapter. The appendix includes the Declaration of Independence, an annotated Constitution, and annotated copies of Federalist 10, 51, and 78. The annotated versions of the Constitution and Federalist Papers are extremely detailed and would be very beneficial to students who have little experience reading historical documents.

The text includes several reoccurring features in each chapter, each ending with three critical thinking questions, which could provide fodder for in-class discussions or for short homework assignments. "Take a Closer Look" emphasizes visual analysis by using a photo or image to highlight aspects of the topic. "Explore Your World" provides a comparative perspective, with an emphasis on visual literacy; it has an anecdotal feel and does not provide students with empirical differences between countries or a robust introduction to the comparative method. "The Living Constitution" examines a topic in light of the text of the Constitution. The section begins with a brief excerpt from the Constitution followed by a short explanation of how the section has been interpreted and the ways in which it has affected political decisions. Finally, most chapters include a section posing a question and providing a visual display of data to address the question.

Each chapter includes bolded key terms with definitions in the margins, chapter review, list of key terms with corresponding page numbers, and a practice quiz. Students have more resources available online, as this text can also be paired with either MyPoliSciLab or REVEL. Of these two options, REVEL is more user friendly for both students and instructors.

Instructors have access to the standard offering of resources including a test bank, instructor's manual, PowerPoint slides, and supplemental resources. Both MyPoliSciLab and REVEL allow instructors to customize the course material and track students' progress. The REVEL interface is much cleaner, it guides students more smoothly through the learning process, and instructors will find it easier to set up and to navigate. The text also comes in an Essentials version (14 chapters) which fuses several of the political behavior and policy chapters. Students can also choose a loose leaf or electronic version of the full text for a slight savings.
American Government: Roots and Reform is a good option for instructors who want to emphasize the historical context for government (APD scholars might be particularly interested in this text). It features exceptionally strong coverage of local government, the judicial system, and campaigns and elections. It is not a good choice for those who might want a strong comparative focus, though it does include comparative sections in each chapter. Thought the text identifies important concepts, there is little direct reference to the research or academic debates surrounding those concepts beyond the endnotes. Overall, the text is accessible, the photos and graphics are engaging, and the focus on both historical context and current events keeps the text grounded.

\section{American Government: Institutions and Policies, 15th Edition. By James Q. Wilson, John J. Dilulio, Jr., Meena Bose, and Matthew Levendusky. Boston: Cengage. 524 p. \$266 paper.}

As reflected in its title, American Government: Institutions and Policies focuses on how uniquely American political institutions shape the development of public policy. The text emphasizes the historical roots of American government and situates it within a comparative framework. The authors ask students to consider the issues that matter to them, arguing that the most important factor affecting policy making involves decisions about what is on the policy agenda.

The text features 20 chapters divided into four sections. The first chapter introduces the analytic framework developed by Wilson that focuses on the politics of issues. Wilson's well-known typology suggests the distribution of benefits and burdens helps explain the type of politics that develop. The text includes sidebars in each section that use this framework to explain current debates over public policy. Other chapters in the first section address the Constitution, federalism, political culture, civil liberties, and civil rights. Section two focuses on political behavior with chapters on public opinion, political participation, political parties, elections and campaigns, interest groups, and the media. Voting, which often occupies a separate chapter or is included in chapters on campaigns and elections, is the primary focus of the political participation chapter. The third section focuses on institutions with chapters on Congress, the presidency, the bureaucracy, and the judiciary. The final section includes separate policy chapters focused on domestic, economic, and foreign and military policy. A concluding chapter in this section examines the changes in American democracy. The appendix includes the Declaration of Independence, The Constitution, Federalist 10 and 51 , a list of presidents and congresses, and a glossary.

After a brief introduction, each chapter opens with a "then" and "now" section, briefly comparing a historical and contemporary experience related to the theme of the chapter. Several reoccurring sections appear throughout the text. "Constitutional Connections" addresses historical and contemporary debates over constitutional interpretation. "How Things Work" appears several times in most chapters, providing a deeper explanation of a key concept or policy. "What Would You Do?" presents a short synopsis of a current policy debate framed as a memo from a fictional person and asks students whether they support or oppose action. "How We Compare" presents 
a comparative perspective, but a comparative approach is also woven directly into the text, making this one of the strongest options for instructors who value a comparative focus. "Landmark Cases" lists and summarizes key Supreme Court cases related to the topic.

Students are guided to important concepts through bolded terms in the text and definitions in the margins. Chapters end with a review of learning objectives and a list of supplemental resources, but include no quizzes to assess comprehension of the material. Instead, students are directed to MindTap, Cengage's online learning resource. MindTap is packaged free with new copies of the text and can be purchased separately for a small fee. The program features videos, quizzes, supplemental activities, and a link to the KnowNowAmericanGovernment Blog featuring news clips and explanations of current political events. MindTap also allows students to access the ebook version of the text.

Instructor resources include an instructor website, test bank, and multimedia supplements. Instructors can customize the MindTap experience for students, changing the order of topics, adding or deleting assignments and readings, and setting deadlines and assignment values. Instructors can track student progress and grades in MindTap or can integrate the program into most major learning management systems including Blackboard, Moodle, D2L, and Canvas.

The text comes in one alternate format, but both can be purchased in bound or loose leaf versions if cost is an option. The brief version of the text features 15 pared down chapters. This text omits the chapters on political culture and economic policy and fuses chapters on public opinion and media and political parties and interest groups. The content of the other chapters, including graphics and sidebars, is mostly identical to the full text.

American Government: Institutions and Policies is a good choice for instructors who want a theory-driven text that emphasizes historical context and a comparative framework. More so than any other text reviewed here, this one summaries key debates within the field and directly identifies the scholars who have made important contributions to our understanding of the topics directly in the text rather than in endnotes. Because the text introduces students to theories and models of the study of political science, it provides an excellent foundation for upper level American government classes.

\section{NOTES}

1. The table of contents in the 1oth edition does not list the policy chapters, but they are included in the book.

2. The website currently lists an option for SAGE Edge Select as well, but company representatives say that the program is being discontinued.

\section{REFERENCES}

Allen, Marcus D. and Sherri L. Wallace. 2010. "Teaching Introduction to American Government/Politics: What We Learn from the Visual Images in Textbooks." Journal of Political Science Education 6 (1): 1-18.

Cassese, Erin C., Angela L. Bos, and Monica C. Schneider. 2014. "Whose American Government? A Quantitative Analysis of Gender and Authorship in American Politics Texts." Journal of Political Science Education $10(3): 253-72$.

Eisenstein, Marie A. and April K. Clark. 2013. "Portraits of Religion in Introductory American Government Textbooks: Images of Tolerance or Intolerance." Journal of Political Science Education 9 (1): 89-107.

Eksterowicz, Anthony J. and Paul C. Cline. 1991. "Ratification of the Constitution: The Great Debate as Portrayed in American Government Textbooks." PS: Political Science \& Politics 24 (2): 211-215

Eksterowicz, Anthony J. and Robert P. Watson. 200o. "Treatment of First Ladies in American Government and Presidency Textbooks: Overlooked, yet Influential, Voices." PS: Political Science \& Politics 33 (3): 589-95.

Evans, Jocelyn Jones and David Lindrum. 2013. "Telling the Story of the American Presidency: Examining the Content and Perspective of Presidency Chapters in Introductory American Politics Texts." Journal of Political Science Education 9 (1): 108-26.

Fairbanks, J. David. 1986 "Religion and Morality in American Political Life: What Do the Textbooks Say?” PS: Political Science \& Politics 19 (4): 869-71.

Franke, Jim and Laurie M. Johnson Bagby. 2005 "The American Founding, American Government Textbooks, and Civic Education." Journal of Political Science Education 1 (2): 249-71.

Goldstein, Robert Justin. 1985. "The FBI and American Politics Textbooks." PS: Political Science \& Politics 18 (2): 237-46.

Lorenzo, David J. 1999. "Countering Popular Misconceptions of Federal Bureaucracies in American Government Classes.” PS: Political Science \& Politics 32 (4): 743-47.

Madsen, Poul Thøis. 2011. "How Do Five American Political Science Textbooks Deal with the Economic Dimension?" Journal of Political Science Education 7 (1): 79-94.

Monforti, Jessica Lavariega and Adam McGlynn. 2010. "Aquí Estamos? A Survey of Latino Portrayal in Introductory US Government and Politics Textbooks." PS: Political Science \& Politics 43 (2): 309-16.

Novkov, Julie and Charles Gossett. 2007. "Survey of Textbooks for Teaching Introduction to US Politics: (How) Do They See Us?" PS: Political Science \& Politics 40 (2): 393-98.

Olivo, Christiane. 2012. "Bringing Women in: Gender and American Government and Politics Textbooks." Journal of Political Science Education 8 (2): 131-46.

Wallace, Sherri L. and Marcus D. Allen. 2008. "Survey of African American Portrayal in Introductory Textbooks in American Government/politics: A Report of the APSA Standing Committee on the Status of Blacks in the Profession.” PS: Political Science \& Politics 41 (1): 153-16o. 